\title{
MANAGING BETTER: CHILDREN, PARENTS, AND ASTHMA*
}

NOREEN M. CLARK ${ }^{a}$, CHARLES H. FELDMAN ${ }^{b}$, DAVID EVANS ${ }^{b}$, OLYA DUZEY $^{a}$, MOSHE J. LEVISON ${ }^{b}$, YVONNE WASILEWSKI ${ }^{b}$, DEBORAH KAPLAN ${ }^{b}$, JILL RIPS ${ }^{b}$ and ROBERT B. MELLINS

a Department of Health Behavior and Health Education, University of Michigan School of Public Health, Ann Arbor, MI and bepartment of Pediatrics, Columbia University College of Physicians and Surgeons, New York, NY (U.S.A.)

(Received May 20th, 1985)

(Revision received September 23rd, 1985)

(Accepted September 30th, 1985)

\section{ABSTRACT}

To evaluate a health education program to improve family management of asthma, 310 childien with asthma and their 290 parents were randomly assigned to a program or control group. Program families participated in health education designed to resolve specific management problems and build self-confidence in the ability to manage asthma. Following education, program parents scored better on an asthma self-management index than parents in the control group $(+1.57$ versus $-0.83, P<0.0001)$. Program parents also scored better on two subindices of the self-management index: attack management $(+0.87$ vs. $+0.42, P<0.05)$ and preventive measures ( +0.42 vs. $-0.35, P<0.05)$. Also, program parents reported significantly more use of guidelines to determine appropriate levels of physical activity for children. Following education, program children reported more use of three management steps than control children: productive cough or postural drainage $(59 \%$ vs. $35 \%, P<0.004)$, breathing and relaxation exercises $(80 \%$ vs. $65 \%, P<0.05)$, and attempts to stay calm $(12 \%$ vs. $2 \%, P<0.05)$. Program children reported significantly less worry than control children about the limitations asthma imposes and about making mistakes at school.

Key words: Asthma - Self-management - Children - Family education

*The work described in this paper was supported in part by contract No. 1-HR-7-2973 and by grant No. 1-R18-HL-28907 from the Lung Division, National Heart, Lung and Blood Institute. 


\section{INTRODUCTION}

Several recent studies involving patient education [1-3] have focused on self-management of chronic disease. The successful management of a chronic disease generally necessitates a medical regimen. For most regimens to be implemented successfully, patients and physicians must communicate frequently so that they can monitor and adjust medications. In addition, for diseases involving acute episodes, patients must be capable of making effective judgments and taking appropriate actions during these episodes. Also, patients must make changes in their routine so that living with the disease and the medical regimen is as normal as possible.

We have previously used the term 'family management' [4] in referring to self-management situations where the patient is a child. This seems an accurate phrase because (1) the members of a family must collaborate to handle the various aspects of disease and (2) parents must assume responsibility for tasks children are too young to perform. The literature to date provides little information about the age when children reach optimum independence as managers of their own health problem. Some investigators report that children can be taught important management skills at very early ages [5]. Others have noted that skills may be deficient well into adolescence [6]. Understanding self-management when the self is a child is also clouded by measurement problems. It has been suggested that some attempts to assess children's behaviors may actually assess parents' behavior. Lewis and Lewis [7], for example, reported that children in an adult-free setting used health services in a pattern different from that used when their parents were involved. A parent, therefore, may not be the best source of information about a child's feelings and behavior regarding health. Although our current knowledge about children as independent managers of health is limited [8], parent and child do interact to an important degree in the effort to manage a disease.

The current project was part of a large study to determine the effect of a health education program on family management of asthma, health care utilization, and a child's school performance. We have previously reported that following education, significant decreases were found in hospitalizations and emergency room visits among children with a history of hospitalization [9]: Also noted was significant improvement in children's grades and school adjustment [10].

It has been suggested that while the benefits of health education may include such outcomes as changes in health care utilization, health status, and in related concerns such as school or job performance, the critical measure of the effectiveness of programs should be their impact on health behavior. According to Green [11] the evaluation of health education should use behavioral change as the dependent variable, and should select behavioral variables according to their presumed association with health status and related outcomes. This paper explores the extent to which the feelings and behavior of parents and children changed with respect to managing asthma at 
home as a result of their participation in an asthma health education program.

Prior studies of asthma self-management behavior have focused on adults [12] or small samples of children [13-15]. No previous work has investigated the impact of health education on the ability of a large number of parents and their children to manage the disease. No study has focused on children in low-income families. None has used as measures children's reports of their own behavior and feelings regarding asthma. The hypotheses of this study were that the health education program would (1) increase the asthma management activities carried out by both parents and children, (2) increase parents' confidence in their ability to manage asthma and (3) reduce negative feelings of children about themselves associated with asthma.

\section{THE EDUCATIONAL PROGRAM}

Development of the program has been presented in detail elsewhere [16]. Following extensive preliminary interviews with children with asthma, their parents and physicians, six topics were identified and these served as themes around which to organize family learning activities. The topics were: How to help your child (yourself) to take medicine; how to set realistic guidelines for your child's (your own) activities; how to take care of an attack at home; how to get information from the doctor; how to keep your child (yourself) healthy; how to help your child (yourself) do well in school. Educational sessions were held weekly in the clinics of four New York City hospitals. They were conducted in Spanish or English by a health educator. During five sessions parents and children met separately and in one they met together.

The education for parents was based on two theoretical ideas from the literature on learning. First was Freire's [17] precept that dialogue among adults stimulated by a picture or story reflecting their everyday experience leads to sophisticated analysis and problem solving even among those with little or no formal education. Second was Bandura's [18] idea that learning is determined to a large degree by people's belief in their own competence to perform new tasks. This precept is termed self-efficacy. Piaget's theory of developmental stages was the basis for developing the children's program [19]. For children 4-7 years of age the emphasis was play, for those 8-12 mastery, and for those 13-17 social relationships. Developing self-efficacy was also a goal for children. Children 4-7 years of age were grouped together and techniques such as story telling and games were used to maintain their interest. We found that children 8-12 could be taught in a single group with those 13 or older when the health educator acknowledged and addressed the needs and interests of the two age levels. For children 8-12 the emphasis was on their performance of management tasks. For older children social function and interaction were emphasized. Older children frequently assisted health educators in the educational process for younger children, and this involvement in teaching was encouraged. 
In each educational session, parents and children were presented with problems uncovered in the preliminary interviews. Problems were presented as anecdotes or scenarios, and whenever possible the actual language was used from descriptions provided by families. Some problems were in the form of short, illustrated dramas for adults, and cartoons and puppet shows for children. There were two characteristics of educational sessions for parents and older children. First, the health educator engaged group members in discussion and led them through steps of problem-solving to arrive at specific actions families might take given a problem. Skills were rehearsed (such as asking the physician for information) and specific strategies developed (such as outlining a sequence of activities to be taken in the event of an emergency). During sessions, families were helped to identify early warning signs of an attack; specify steps for managing an attack at home; identify a serious wheezing episode; and use a specific set of guidelines to determine what physical activities a child with asthma is able to do. Second, the group process used by the health educator while leading these problemsolving discussions emphasized the extensive experience each family had with the disease, and underscored that this experience could help them to make needed management decisions. The health educator verbally encouraged and praised parents and children to indicate that their own analyses of problems were valid and their judgments sound. Health educators were trained prior to the program on how to be empathetic, how to conduct problem-solving discussions, and how to reinforce participants' confidence in their own good ideas and decisions.

\section{THE EVALUATION OF THE EDUCATIONAL PROGRAM}

\section{The Study population}

Families were enlisted for the study from the pediatric allergy clinics at Harlem, St. Luke's-Roosevelt, and Presbyterian Hospitals in New York City. Children were eligible if the following conditions were fulfilled: A diagnosis of asthma made by a physician; one or more visits to the clinic in the previous 12 months; one or more episodes of wheezing reported in the prior year; age between 4 and 17 years; and no major handicap that would prevent benefit from an educational program.

From a pool of 558 families determined to be eligible after review of their medical records, we were able to contact 368 . The most frequent reason for making no contact was that families had moved. At the time of a regularly scheduled clinic visit families were invited to participate and signed consent forms. Thirty-six parents (or adult caretakers responsible for the child) declined to participate and 42 families did not complete interviews conducted prior to the program. Thus 290 parents with 310 children were enrolled in the study. Families were predominantly black or Hispanic. The mean age of the children was 9.2 years and $64 \%$ were male. The majority of families received public assistance. 
Our intention was to recruit a sample representative of the entire clinic population of children with asthma. As a first check on the representativeness of the sample, data from medical records were compared for the 310 enrolled and 248 non-enrolled children. As a second check, records available for 174 children using clinic services 2 years prior to initiation of the study were reviewed. Data for 30 children who subsequently agreed to participate in the program were compared with data of the 144 who stopped attending the clinic or refused to participate. In both comparisons, no significant differences were noted in race, sex, or distance of residence from the clinic. Non-enrolled children were slightly older than enrolled in both comparisons (mean age 9.2 vs. $11.0, P<0.05$ ). This difference may be attributed to the fact that asthma tends to cause more severe problems for younger children and during adolescence the children are less likely to use clinic services. On the basis of these comparisons the sample appears to be representative of the clinic population.

\section{Evaluation design and measures}

After signing consent forms, parents and children were interviewed separately in English or Spanish. Following the interview, children were randomly assigned in a $2: 1$ ratio into a program group $(n=207)$ that received the health education program or a control group $(n=103)$ that did not receive the program; both groups received routine clinic medical care. All siblings were assigned to the same group. There were no significant differences in demographic variables between the program and control groups. One year following the educational program, parents and children were re-interviewed (medical and school records were also reviewed to obtain health care utilization and school performance data).

An asthma management index was constructed for adults from interview questionnaire items. The index consisted of behaviors mentioned frequently by parents and physicians as potentially useful in reducing the disruption in family life produced by asthma. It was divided into three subindices: Seeking information and support; behavior during an asthma attack; preventive measures. Table I outlines the subindices. A Cronbach Alpha statistic was computed to determine how each item in the overall index related to all the other items. Alphas were also computed to assess how each item on the subindices related to the other items on that same index. The alpha statistics were as follows: For the overall index 0.71 , for the seeking information subindex 0.45 ; for the attack management subindex 0.51 , and for the prevention subindex 0.52 . These scores indicate that the items of the overall index and subindices had adequate internal consistency as measures of asthma management. The number in the parent's sample for whom there were both pre and post program data on the attack management and seeking information indices was 225. Questions forming the subindex on prevention were asked only of the first 100 respon- 


\section{TABLE I}

\section{ITEMS OF THE ASTHMA MANAGEMENT INDEX FOR PARENTS OF CHILDREN} WITH ASTHMA

Subindex 1 -Seeking information and support:

(1) Parent asks doctor questions

(2) Reads or hears about asthma in any of several media sources during the last year

(3) Talks with school teacher about child's asthma

Subindex 2 - Parents' behavior during wheezing or asthma attack:

(1) Gives child asthma medicine during most recent attack

(2) Has child perform breathing or relaxation exercises during recent attack

(3) Performed productive cough or postural drainage during recent attack

(4) Any other management activity reported during recent attack.

These measures include:

(a) calling a friend for advice or help

(b) using a home remedy (which was not considered deleterious to the child's health)

(c) parent calming herself to maintain relaxed environment

(d) other actions voluntarily recalled by parent

(5) Parent gives liquids to child to maintain normal fluid intake during wheezing episode

(6) Parent feels confidence in own ability to manage asthma.

Subindex $3-$ Preventive measures:

(1) Gives child medications as needed to prevent symptoms in situations which parent has identified as likely to cause symptoms, including:

(a) when child has cold or infection

(b) before exercise

(c) before exposure to known allergens (i.e. a relative's perfume and/or pet)

(2) Cleans house in a special way to prevent build-up of allergens and irritants

(3) Keeps child away from other children with colds or infections

(4) Removes common or known allergens from child's environment

(5) Maintains child's normal fluid intake on daily basis

(6) Has child practice breathing and relaxation exercises regularly

dents, then dropped in order to expidite interviews by using a shorter version of the questionnaire. Therefore, the number of responses for that subindex and the overall self-management index is 100 . Other questionnaire items regarding parents' management of asthma and their feelings about the disease were analyzed as single items and the number of responses was 225 . The attrition rates for the program and control groups from pre test to post test were not significantly different.

Items in the child questionnaire required that children 8 through 17 report their own behavior at the time of the last attack. Did they: Take their medicine, rest, drink some fluid, do something to help stay calm, tell an adult how they were feeling, try breathing or other relaxation exercises (breathing exercises were included only for purposes of relaxation), do 
postural drainage or productive couch? Children were also asked to report their feelings of worry or shame associated with asthma.

The number of responses in the child sample presented here is less than the 310 enrolled in the study. Because the process for posing questions to children between 4 and 7 years was substantially different from the process for interviewing older children, data for 4-7-year-olds will not be reported. Items related to feelings were included in a long form of the questionnaire and were asked only of the first 100 older children interviewed. Further, children were not pushed in any way to respond to questions when they were shy or reluctant; therefore, there were some missing data. The number of children providing responses related to asthma management was 165 and the number providing responses related to feelings was 70 . The 70 children answering questions about their feelings and the 165 answering about asthma management were compared respectively with the total group of 100 children who were asked questions about feelings and 214 who were asked management questions. No significant differences were seen in these comparisons on the variables of age, sex, race, and distance of residence from the clinic, which suggests that the smaller groups are representative of the large ones. Children remaining in the control and program groups responding to each type of question were compared on the same variables. There were somewhat more Hispanic children who responded to management questions in the program group than in the control group, but this difference was not statistically significant. There was, however, a larger number of program children 12 years or older than control children who responded to questions regarding feelings about asthma $(P<0.006)$. This fact means that caution must be used in interpreting findings related to children's feelings. It may be that program children responded differently than control children simply because they were older. No significant differences were noted on any other demographic variables between groups responding about asthma management and feelings. Comparisons between program and control group responses following the educational intervention are presented. Too few children provided data both before and after the program to enable analysis of pre to post change.

\section{Data analysis}

Analysis of variance was used to ascertain differences in parents' mean scores on the management index pre to post education between the program and control groups. While there were no statistically significant differences between experimental and control groups' baseline scores, we felt it was more precise to test the statistical significance of the difference scores rather than the post education scores in order to eliminate small differences, if any, in baseline scores. The $\chi$-square statistic was used to ascertain differences between program and control group responses on individual questionnaire items for both parents and children. Statistical significance was set at the 0.05 level. 


\section{FINDINGS}

\section{Parents}

Table II presents mean scores pre to post program on the parent asthma management index and subindices. The mean score for the program group on the overall index increased significantly pre to post program. When difference scores of program and control groups were compared, the program parents' scores were significantly higher. When subindices were considered separately, difference scores for program parents were significantly higher than those of control group parents on the subindices related to preventive measures and managing an asthma attack. Differences between program and control parents on the seeking information and support subindex were not significant.

Other findings suggest that the program had an impact on the way parents set guidelines for children's physical activity. Table III shows that significantly more program parents set limits for the child as opposed to having no restrictions. In addition, when asked how disagreements between parent and child over asthma care were resolved, a significantly greater number of program group parents said they asked children to demonstrate how they

\section{TABLE II}

\section{PARENT SELF-MANAGEMENT INDEX SCORES}

Analysis of variance: In the total Index, there is a significant interaction between year (pre-post) and group (exp-control) $(P<0.0001)$. In Subindex 1 there is a main effect for year $(P<0.05)$ and a group $\times$ year interaction approaching significance $(P<0.06)$. In Subindex 2 , there are main effects for year and group $(P<0.0001)$ and a group $\times$ year interaction $(P<0.05)$. In Subindex 3 , there is a group $\times$ year interaction $(P<0.05)$.

\begin{tabular}{lrrrl}
\hline Variable & Group & & \\
\cline { 3 - 5 } & & Experimental & Control & Significance $^{\mathrm{a}}$ \\
\hline Self-Management Index $(n=84):$ & & & & \\
Pre intervention & & 9.68 & 9.04 & \\
Post intervention & & 10.25 & 8.21 & \\
Difference & & +1.57 & -0.83 & $P<0.0001$ \\
Subindex 1 $(n=183):$ & pre & 2.06 & 2.19 & \\
& post & 2.01 & 1.81 & \\
Seeks information and support difference & -0.05 & -0.38 & $P<0.06$ \\
Subindex 2 $(n=198)$ & pre & 3.87 & 3.79 & \\
Attack management & post & 4.74 & 4.21 & \\
& difference & +0.87 & +0.42 & $P<0.05$ \\
Subindex 3 $(n=90)$ & pre & 2.95 & 3.06 & \\
Preventive measures & post & 3.37 & 2.71 & \\
& difference & +0.42 & -0.35 & $P<0.05$ \\
\hline
\end{tabular}

a $x$-Square test. 
TABLE III

PARENTS' BEHAVIOR : ESTABLISHING GUIDELINES FOR THE CHILD'S ACTIVITY

\begin{tabular}{llll}
\hline Post program year & $\begin{array}{l}\text { Program } \\
(\%)\end{array}$ & $\begin{array}{l}\text { Control } \\
(\%)\end{array}$ & Significance $^{\mathrm{a}}$ \\
\hline $\begin{array}{l}\text { Parent reports setting limits on the child's } \\
\quad \text { activity to prevent wheezing }\end{array}$ & 46 & 31 & $P<0.05$ \\
$\begin{array}{l}\text { Parent prohibits outdoor play } \\
\begin{array}{l}\text { Parent has child demonstrate wheezing } \\
\quad \text { control skills before making decision }\end{array}\end{array}$ & 5 & 13 & $10<P>0.05$ \\
$\quad$ about activity & 70 & 38 & $P<0.01$ \\
\hline
\end{tabular}

${ }^{a} x$-Square test.

would monitor and control wheezing during physical activity. Fewer program parents prohibited outdoor play but this finding was not statistically significant.

\section{Children}

Children in the program group showed significant improvement over control children following the educational program in three of the seven child management activities. Table V presents children's reports of their attempts to use postural drainage or productive cough, use breathing or relaxation exercises, and stay calm.

Among children who answered post education questions related to their feelings, program group children felt significantly less worried or ashamed on two items than did control group children. Program children reported that they worried less about being unable to do things because of asthma (51\% vs. $88 \%, P<0.006$ ). When asked what made them feel ashamed, children who

\section{TABLE IV}

CHANGES IN CHILDREN'S ASTHMA MANAGEMENT ACTIVITIES

\begin{tabular}{llll}
\hline Post program year & $\begin{array}{l}\text { Program } \\
(\%)\end{array}$ & $\begin{array}{l}\text { Control } \\
(\%)\end{array}$ & Significance $^{\mathrm{a}}$ \\
\hline $\begin{array}{l}\text { Used postural drainage or productive } \\
\quad \text { cough always or sometimes }\end{array}$ & 59 & 35 & $P<0.004$ \\
$\begin{array}{l}\text { Used breathing or other relaxation } \\
\quad \text { exercises always or sometimes }\end{array}$ & 80 & 65 & $P<0.05$ \\
\begin{tabular}{l} 
Tried to find ways to stay calm \\
\hline
\end{tabular} & 12 & 2 & $P<0.05$ \\
\hline
\end{tabular}

${ }^{a} \mathrm{x}$-Square test. 
took part in the education program reported much less often that they were ashamed about making mistakes at school ( $49 \%$ vs. $94 \%, P<0.0009)$. Fewer program group children reported that they were ashamed of having an asthma attack when other people were around; however, this finding was not statistically significant $(39 \%$, vs. $65 \%, P<0.057)$. No other differences related to a child's worry or shame were significant.

\section{DISCUSSION}

The health education program appears to have had significant impact on parents' overall ability to manage the child's asthma. Program parents' higher scores on the attack management and prevention subindices indicate that avoiding and treating the wheezing episode were priorities for adults. The health education appears to have provided useful skills or given parents confidence to use their existing skills.

The finding that parents asked children to demonstrate wheezing control skills before decisions were made about their physical activities indicates that program parents were involving children in the process of setting guidelines. It also suggests that parents were relying more on the child's capability to engage in self-management and responsibility for some wheezing control was shifting to the child. It may be that parental behavior combined with the health educator's assurances that play and other physical activities are safe for individuals with asthma led program children to feel less worried and restricted by the disease. One, however, must be cautious in making such interpretations about findings from the children's sample related to feelings. These responses may be biased, since program children as a group were somewhat older than control children.

Of the seven child management items, increases were observed in three related to staying calm, employing relaxation exercises, and performing productive cough. It is likely that these behaviors were novel for children, and this may account in part for their interest in learning and using them. The other behaviors (rest, medicine, fluids, talking to an adult) constitute advice that physicians and parents often give. In addition, the three novel behaviors lend themselves well to rehearsal, and specific techniques were practiced by children during each educational session.

It is interesting to speculate about the finding that program children were less ashamed about making errors at school. We have previously reported that children in the program had significantly higher school grades compared to controls [10]. The program used the processes of discussion and problem solving and focused on building confidence in one's ability to express ideas and find solutions. As a result of participation, children may have felt less embarrassed about making errors in the classroom. Being less fearful may have led to more efforts to offer ideas and to better school performance. 


\section{IMPLICATIONS FOR PRACTITIONERS}

The data presented here show that health education to improve family management of asthma significantly increased the number of management actions taken at home by both parent and child. The program also appears to have significantly reduced the extent to which children worried about being restricted by the disease and helped them feel less ashamed about making mistakes at school.

The findings suggest to practitioners that the problem-centered, confidence-building approach to patient education is efficacious for both parents and children. While some practitioners address teaching efforts solely to parents and rely on parental descriptions of a child's feelings and illness experience, these data imply that by 8 years of age, children can identify and articulate problems related to their disease and engage in problem solving. The data suggest as well that patient education can not only improve at-home management of asthma but may also yield benefits to the family in the areas of childrens' self-confidence and school performance.

\section{REFERENCES}

1 Green LW, Goldstein RA, Parker SR: Self-management of childhood asthma. J. Allergy Clin Immunol 1983; 72 (5 part 2): 519-626.

2 Speers MA, Turk DC: Diabetes self-care: Knowledge, beliefs, motivation, and action. Pat Couns Health Educ 1982; 144-149.

3 Brough FK, Schmidt CD, Rasmusson T, Boyer M: Comparison of two teaching methods for self-care training for patients with chronic obstructive pulmonary disease. Pat Couns Health Educ 1982; 4:111-116.

4 Clark NM, Feldman CH, Evans D, Wasilewski Y, Millman JM, Valle I: The effectiveness of education for family management of asthma: A preliminary report. Health Educ Q 1982; 8: 166-174.

5 Etzweiler DD, Robb JR: Evaluation of programmed education among juvenile diabetics and their families. Diabetes $1972 ; 21: 967-971$.

6 Johnson SB, Pollak RT, Silverstein JH, Rosenbloom AL, Spillar R, McCallum M, Harkavy. Cognitive and behavioral knowledge about insulin-dependent diabetes among children and parents. Pediatrics 1982;69: 708-713.

7 Lewis C, Lewis MA: Improving the health of children: Must children be involved? Annu Rev PH 1983; 4: 259-283.

8 Clark NM, Shope J: The current knowledge base for health education programs for chronically ill children. Adv Health Educ in press.

9 Clark NM, Feldman CH, Evans D, Levison M, Wasilewski Y, Mellins RB: The impact of health education on frequency and cost of health care utilization by low income children with asthma J. All Clin Immunol, 1986; in press.

10 Clark NM, Feldman CH, Evans D, Wasilewski Y, Levison M: Changes in children's school performance as a result of education for family management of asthma. J Sch Health $1984 ; 54: 143-145$.

11 Green LW: Evaluation of patient education programs: Criteria and measurement techniques. RX: Education for the patient, who, what, where, why. . . and at what cost? Department of Health Education, Southern Illinois University, USDHEW, PHS, June 1974. 
12 Green LW, Werlin S, Schauffier H, Avery C: Research and demonstration issues in self-care: Measuring the decline of mediocentrism. Health Educ Monogr 1977; 5: $161-189$.

13 Fireman P, Friday G, Gira C, Viethaler W, Michaels L: Teaching self-management skills to asthmatic children and their parents in an ambulatory setting. Pediatrics $1981 ; 68: 341-348$.

14 Hindi-Alexander MC, Cropp GJA: Evaluation of a family asthma program. J. Allergy Clin Immunol 1984; $74: 505-510$.

15 Lewis CE, Rachelefsky G, Lewis MA, de la Sota A, Kaplan M: A randomized trial of A.C.T. (Asthma Care Training) for kids. Pediatrics 1984; 74:478-486.

16 Clark NM, Feldman CH, Freudenberg N, Wasileski Y, Valle I: Developing education for children with asthma through study of self-management behavior. Health Educ $\mathbf{Q}$ $1980 ; 7: 278-296$.

17 Freire P: Pedagogy of the oppressed. New York: Seabury Press, 1970.

18 Bandura A: Social learning theory. Prentice-Hall Inc.; New Jersey: Englewood Cliffs, 1977.

19 Schwebel M, Raph J: Piaget in the classroom. New York: Basic Books Inc., 1973. 